\title{
Effects of an EGFR-binding affibody molecule on intracellular signaling pathways
}

\author{
E. NORDBERG ${ }^{1}$, L. EKERLJUNG ${ }^{1}$, S.H. SAHLBERG ${ }^{1}$, J. CARLSSON ${ }^{1}$, \\ J. LENNARTSSON ${ }^{2}$ and B. GLIMELIUS ${ }^{3}$
}

\begin{abstract}
${ }^{1}$ Biomedical Radiation Sciences, Department of Oncology, Radiology and Clinical Immunology, Rudbeck Laboratory, Uppsala University, SE-751 85 Uppsala; ${ }^{2}$ Ludwig Institute for Cancer Research, Uppsala University, Box 595, SE-75124 Uppsala; ${ }^{3}$ Section of Oncology, Department of Oncology, Radiology and Clinical Immunology, Uppsala University, SE-751 85 Uppsala, Sweden
\end{abstract}

Received October 27, 2009; Accepted December 14, 2009

DOI: 10.3892/ijo_00000576

\begin{abstract}
Effects on intracellular signaling were studied in cells treated with the affibody molecule $\left(\mathrm{Z}_{\mathrm{EGFR}: 955}\right)_{2}$ that targets the epithelial growth factor receptor (EGFR). EGFR is overexpressed in many types of cancers and plays a fundamental role in cell signaling and it is of interest to find targeting agents capable of blocking the receptor. The clinically approved antibody cetuximab (Erbitux ${ }^{\circledR}$ ) and the natural ligand EGF were included as reference molecules. Two EGFR-rich cell lines, A-431 and U-343, were exposed to the three targeting agents and lysed. The cell lysates were immunoprecipitated with the receptors, or directly separated by SDS-Page. Autophosphorylation of the receptors and phosphorylation of the downstream signaling proteins Erk and Akt, were evaluated by Western blotting. Although the three different agents compete for the same binding site on EGFR, they influenced the signaling differently. The affibody molecule did not induce autophosphorylation of EGFR or any other receptor in the EGFR-family but, in spite of this, induced phosphorylation of Erk in both cell lines and Akt in the A-431 cells. Thus, the results suggest that the signaling pattern induced by $\left(\mathrm{Z}_{\mathrm{EGFR}: 955}\right)_{2}$ is only partly similar to that induced by cetuximab. This makes the affibody molecule a potentially interesting alternative to cetuximab for EGFR-targeted therapy since it might give different therapy-related effects on tumor cells and different side effects on normal tissues.
\end{abstract}

\section{Introduction}

The epidermal growth factor (EGF) receptor (EGFR/HER1) is a member of the tyrosine kinase EGFR family that also

Correspondence to: Professor Jörgen Carlsson, Department of Oncology, Radiology and Clinical Immunology, Rudbeck Laboratory, Uppsala University, SE-751 85 Uppsala, Sweden

E-mail: jorgen.carlsson@bms.uu.se

Key words: A-431, affibody, Akt, epithelial growth factor receptor, Erk, signaling, U-343 includes, HER2, HER3 and HER4. This receptor family regulates many important cellular processes such as proliferation, migration, apoptosis and differentiation (1).

The receptors in the EGFR family are composed of an extracellular domain, a transmembrane domain and an intracellular tyrosine kinase domain, which in HER3 lacks kinase activity $(2,3)$. EGFR is activated by ligand binding, leading to autophosphorylation of several intracellular tyrosine residues, which serves as binding sites for signaling molecules containing Src homology 2 domains. Two important pathways activated by the EGFR family are the Erk (MAP kinase) and Akt pathways, mainly leading to cellular proliferation and survival, respectively $(4,5)$.

EGFR is overexpressed in many types of cancers, which makes it an attractive target for both diagnostic and therapeutic applications. Several drugs have been developed with the intention to prevent EGFR receptor signaling, either by blocking the extracellular binding site for EGF or to block the ATP binding domain on the intracellular tyrosine kinase domain (6-8). However, the complexity of signaling networks, and the possible non-optimal properties of drugs applied so far, allows cancer cells to circumvent the therapeutic effects of EGFR targeting $(5,9)$. Therefore, it is important to develop more efficient therapeutic approaches aimed to block EGFR signaling in cancer patients and/or to exploit EGFR overexpression for delivery of cytotoxic agents such as radionuclides. Ideally, such an EGFR targeting agent would, in addition to delivering the cytotoxic agent, also through modulation of intracellular signaling networks sensitize the cell for the cytotoxic effect.

Cetuximab (Erbitux $\left.{ }^{\circledR}\right)$ is a monoclonal antibody approved for treatment of EGFR-positive metastatic colorectal cancer in 2004 and for treatment of advanced squamous cell carcinoma of the head and neck in combination with radiation in $2005(10,11)$. Treatment with cetuximab in combination with chemotherapeutic drugs or radiation is more effective than treatment with cetuximab alone (12).

A new category of molecules called affibody molecules $\left(\right.$ Affibody $\left.{ }^{\circledR}\right)$, are also interesting for EGFR family targeting. Affibody molecules are especially interesting for imaging applications because of their small size (7 or $15 \mathrm{kDa}$, depending 
a

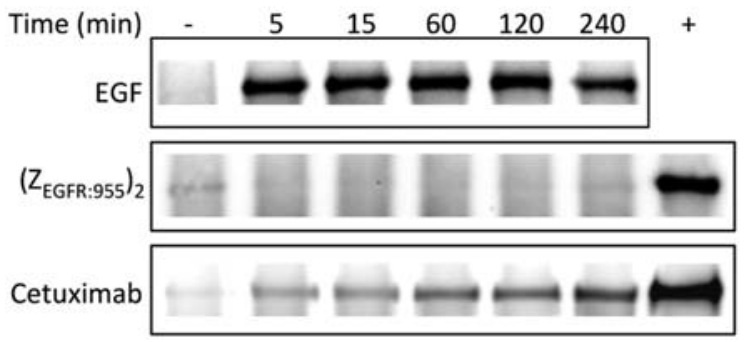

IP: EGFR IB: PY-99 (A-431 cells)

\section{b}

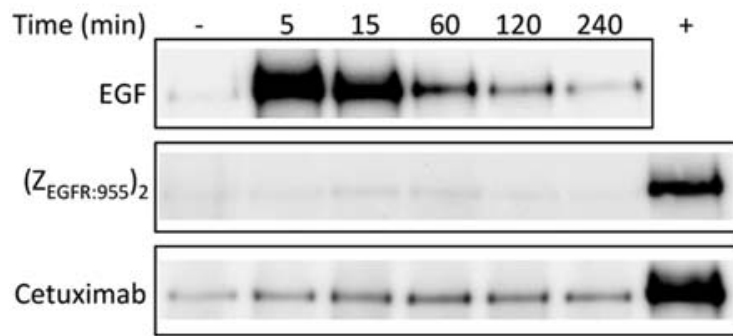

IP: EGFR IB: PY-99 (U-343 cells)

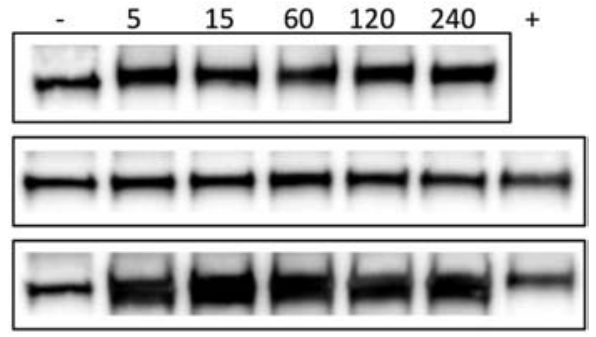

IP: EGFR IB: EGFR (A-431 cells)

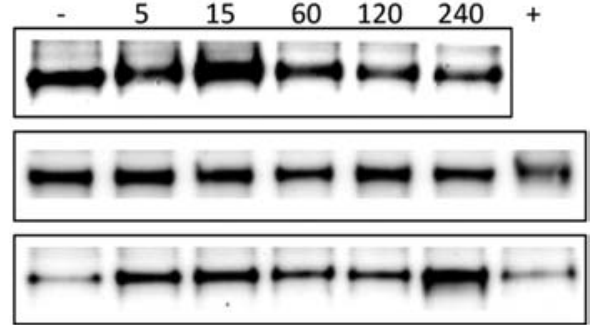

IP: EGFR IB: EGFR (U-343 cells)

Figure 1. Autophosphorylated and total EGFR in A-431 (a) and U-343 (b) cells. Phosphorylations are shown to the left and total EGFR to the right. EGF treatment resulted in activation of the receptor already after 5 min of incubation whereas no induced activation could be detected in cells incubated with $\left(\mathrm{Z}_{\mathrm{EGFR}: 955}\right)_{2}$. However, cetuximab gave autophosphorylation of EGFR in both cell lines. Untreated cells were used as negative controls (-) and cells incubated with EGF for 15 min as positive controls (+).

on monomeric or dimeric state) compared to antibodies $(\sim 150 \mathrm{kDa})(13,14)$. An anti-HER2 affibody molecule, $\mathrm{Z}_{\text {HER2:342 }}$, has recently been tested and it was found to have a potential to be used for imaging of the spatial distribution of HER2 in primary and metastatic breast cancer $(15,16)$. The imaging capacity for the EGFR targeting $\left(\mathrm{Z}_{\mathrm{EGFR}: 955}\right)_{2}$ conjugated with CHX-A"-DTPA and labeled with ${ }^{111}$ In was tested in a previous study (17). The result showed that $\left(\mathrm{Z}_{\mathrm{EGFR}: 955}\right)_{2}$ is a promising agent for EGFR imaging and it is of value to investigate if it also has potential in therapy applications.

In this study, we investigated signaling effects in response to binding of the affibody molecule $\left(\mathrm{Z}_{\mathrm{EGFR}: 955}\right)_{2}$ to EGFR. We compared the signaling patterns with the patterns generated by the natural ligand EGF and the antibody cetuximab. These substances share the same binding site (18) and it is therefore important to explore if they trigger the same signaling pathways.

\section{Materials and methods}

Cell culture. Two cell lines overexpressing EGFR, in the order of $10^{6} \mathrm{EGFR} /$ cell $(18$, and references therein), were used in the cellular experiments: a squamous carcinoma cell line A431 (CRL 1555, LGC-promochem, Borås, Sweden) and the human glioma cell line U-343MGaC12:6 (Department of Genetics and Pathology, Uppsala University, Sweden) (19). The glioma cell line is from now on denoted U-343. Both cell lines were cultured in Ham's F-10 medium, supplemented with $2 \mathrm{mM}$ L-glutamine, PEST (penicillin $100 \mathrm{IU} / \mathrm{ml}$ and streptomycin $100 \mu \mathrm{g} / \mathrm{ml}$ ) and $10 \%$ fetal calf serum (FBS). All reagents were from Biochrom Kg (Berlin, Germany). The cells were cultured in $25 \mathrm{~cm}^{2}$ culture bottles (Nunclon ${ }^{\mathrm{TM}}$ surface, Roskilde, Denmark) grown at $37^{\circ} \mathrm{C}$ in an incubator with humidified air equilibrated with $5 \% \mathrm{CO}_{2}$.

Antibodies and reagents. Antibodies specific for EGFR, HER2-4, Akt and phosphostyrosine (PY-99) were purchased from Santa Cruz Biotechnology (Santa Cruz, CA, USA). Antibodies recognizing phosphorylated Erk (Thr 202/Tyr 204) or Akt (Ser 473) were from Cell Signaling Technology (Beverly, MA, USA). The reagents applied have previously been used and described (20).

Cell lysis. Cells were starved in $0.1 \%$ FBS overnight. At the day of the experiment, one bottle of each cell line was counted in a cell counter (1480 Wizard, Wallac Oy, Turku, Finland) and the number of cells was used to determine which concentration of the three substances, EGF (Chemicon International, Temecula, CA, USA), $\left(\mathrm{Z}_{\mathrm{EGFR}: 955}\right)_{2}$ (Affibody AB, Bromma, Sweden) and cetuximab (Merck, Darmstadt, Germany) should be added to the cells. The cells were treated with a molar excess of 20:1 (molecules:receptor) in $10 \mathrm{ml}$ of medium for different periods of time, ranging from $5 \mathrm{~min}$ to $6 \mathrm{~h}$. After incubation the cells were washed once with cold PBS and lysed in a lysis buffer (1\% Triton X-100, 10\% glycerol, $150 \mathrm{mM} \mathrm{NaCl}, 5 \mathrm{mM}$ EDTA, $20 \mathrm{mM}$ Tris, $1 \%$ Trasylol, $1 \mathrm{mM}$ PMSF and $1 \mathrm{mM} \mathrm{Na} \mathrm{VO}_{4}, \mathrm{pH} 7.4$ ).

Immunoprecipitation and immunoblotting. To obtain the same protein concentration loaded on the gel a $\mathrm{BCA}^{\mathrm{TM}}$ Protein assay 


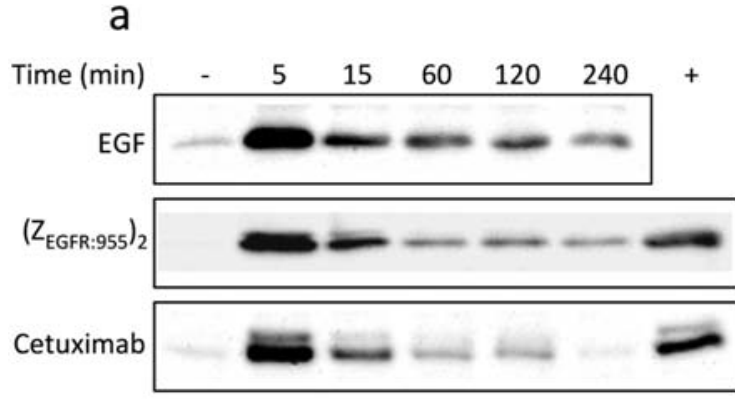

IB: $\mathrm{p}$-ERK (A-431 cells)

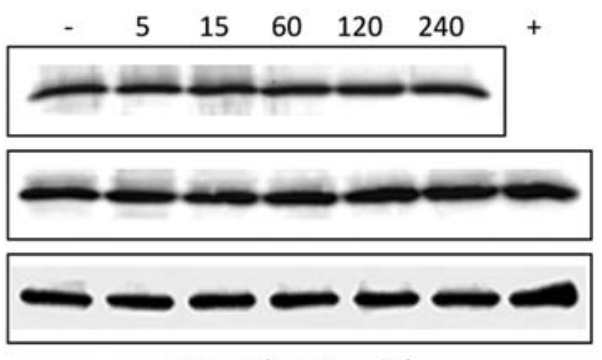

IB: ERK (A-431 cells)

b

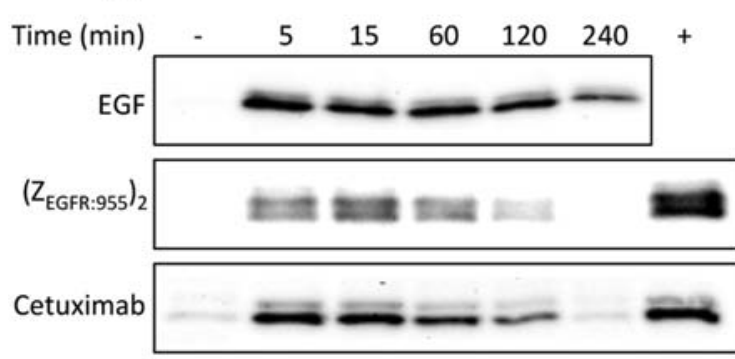

IB: p-ERK (U-343 cells)

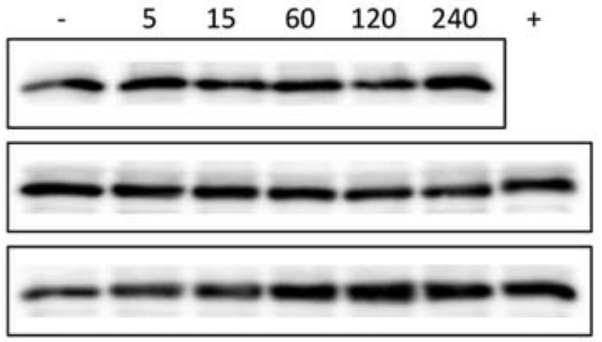

IB: ERK (U-343 cells)

Figure 2. Phosphorylated and total Erk in A-431 (a) and U-343 (b) cells. Phosphorylations are shown to the left and total Erk to the right. A similar pattern could be detected in both cell types. The three substances EGF, $\left(\mathrm{Z}_{\mathrm{EGFR}: 955}\right)_{2}$ and cetuximab phosphorylated Erk already after 5 min of incubation. Untreated cells were used as negative controls (-) and cells incubated with EGF for 15 min as positive controls (+).

kit (Pierce, Rockford, USA) was used. For phosphorylated and total receptor studies, cell lysates were first immunoprecipitated overnight at $4^{\circ} \mathrm{C}$ with antibodies targeting the receptor followed by incubation with protein A-agarose (Santa Cruz) end-over-end rotating for $1 \mathrm{~h}$. The beads were washed 3 times in lysis buffer, re-suspended in sample buffer (100 mM Tris-Cl, 2\% SDS, 20\% glycerol, 10\% ß-merceptoetanol and $0.2 \%$ bromophenol blue) and heated at $95^{\circ} \mathrm{C}$ for $5 \mathrm{~min}$. The samples were thereafter separated by SDS-PAGE ( $8 \%$ acrylamide and transferred to PVDF membranes (Millipore, Billerica, USA). The membranes were blocked in $5 \%$ BSA in phosphate-buffered saline solution containing $0.1 \%$ Tween-20 (PBS-T) and thereafter washed once in PBS-T. Primary antibodies were incubated for $2 \mathrm{~h}$ at room temperature or overnight at $4^{\circ} \mathrm{C}$. After washing in PBS-T, secondary antibodies were added for $1 \mathrm{~h}$ and after additional washing the proteins were visualized using enhanced chemiluminescence Western blotting detection systems on a cooled chargecoupled device camera (FujiFilm, Luminescent Image analyzer LAS-1000 plus).

\section{Results}

Effects on EGFR-autophosphorylation by EGF, $\left(Z_{\text {EGFR:955 }}\right)_{2}$ and cetuximab. A-431 and U-343 cells were treated with EGF, $\left(\mathrm{Z}_{\mathrm{EGFR}: 955}\right)_{2}$ or cetuximab for different periods of time. EGF treatment resulted in receptor autophosphorylation already after $5 \mathrm{~min}$ in both A-431 and U-343 cells, but with a more transient kinetics in U-343 cells. Incubating cells with cetuximab lead to activation of EGFR, although to modest levels compared to that achieved with EGF. However, no induced autophosphorylation of the receptor could be detected when the cells were treated with $\left(\mathrm{Z}_{\mathrm{EGFR}: 955}\right)_{2}$. Thus, even though the three substances share the same binding site, as previously described (18), they affected the receptor autophosphorylation in different ways (Fig. 1).

Effects of EGF, $\left(Z_{E G F R: 955}\right)_{2}$ and cetuximab on intracellular signaling pathways. Next, we investigated effects of EGF, $\left(\mathrm{Z}_{\mathrm{EGFR}: 955}\right)_{2}$ and cetuximab on activation of the intracellular signaling proteins Erk and Akt. Phosphorylation of Erk was induced by all three substances in both U-343 and A-431 cells, as seen in Fig. 2. The increase in Erk phosphorylation was more transient in A-431 compared to U-343 cells.

The phosphorylation status of the anti-apoptotic kinase Akt was also analyzed. In U-343 cells we found that Akt was constitutively phosphorylated and no clear changes were seen after treatment with EGFR, cetuximab or $\left(\mathrm{Z}_{\mathrm{EGFR}: 955}\right)_{2}$. In contrast, Akt was not, or only to a low level, phosphorylated in the absence of stimulus in A-431 cells. Herein, strong phosphorylation of Akt was induced by treatment of EGF, $\left(\mathrm{Z}_{\mathrm{EGFR}: 955}\right)_{2}$ and cetuximab (Fig. 3). Note that both Erk and Akt was phosphorylated by $\left(\mathrm{Z}_{\mathrm{EGFR}: 955}\right)_{2}$, although we could not detect autophosphorylation of EGFR by this molecule.

Comparison of the autophosphorylation pattern between the EGFR-family members when treated with EGF, $\left(Z_{E G F R: 955}\right)_{2}$ and cetuximab. Studies were done in A-431 and U-343 cells to analyze if the undetectable autophosphorylation of EGFR, and the following activation of Erk and Akt after treatment 
a

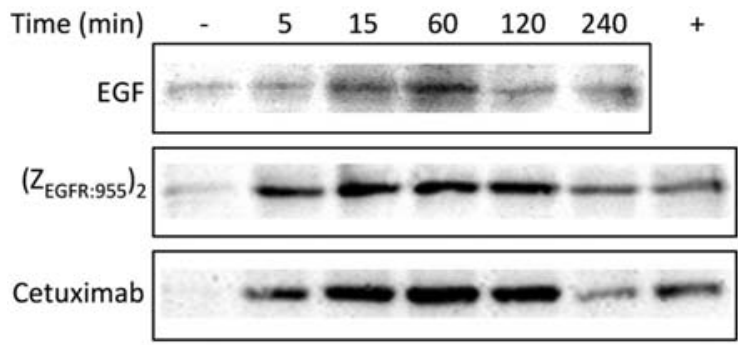

IB: $\mathrm{p}-\mathrm{AKT}$ (A-431 cells)

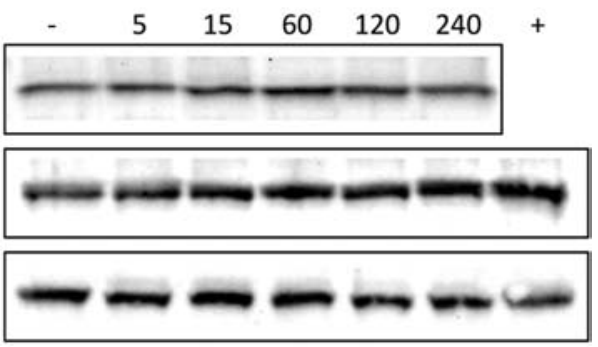

IB: AKT (A-431 cells)

b

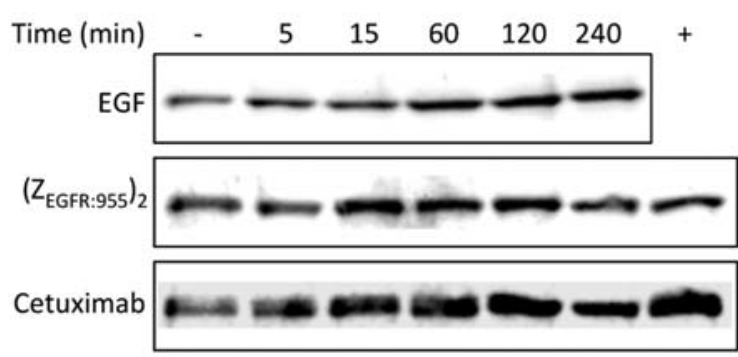

IB: p-AKT (U-343 cells)

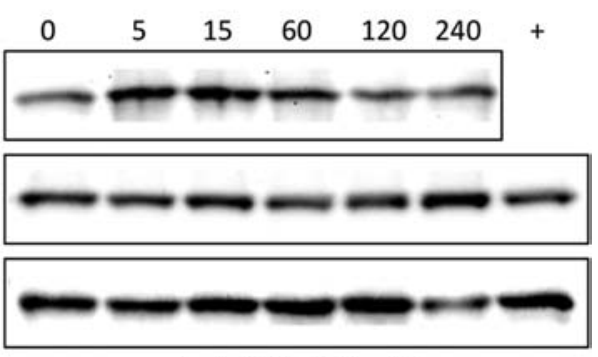

IB: AKT (U-343 cells)

Figure 3. Phosphorylated and total Akt in A-431 (a) and U-343 (b) cells. Phosphorylations are shown to the left and total Akt to the right. Akt was activated by the three substances EGF, $\left(\mathrm{Z}_{\mathrm{EGFR}: 955}\right)_{2}$, and cetuximab in A-431 cells (a). Note that Akt was activated even without addition of the substances in U-343 cells (b). Untreated cells were used as negative controls (-) and cells incubated with EGF for $15 \mathrm{~min}$ as positive controls (+).

a

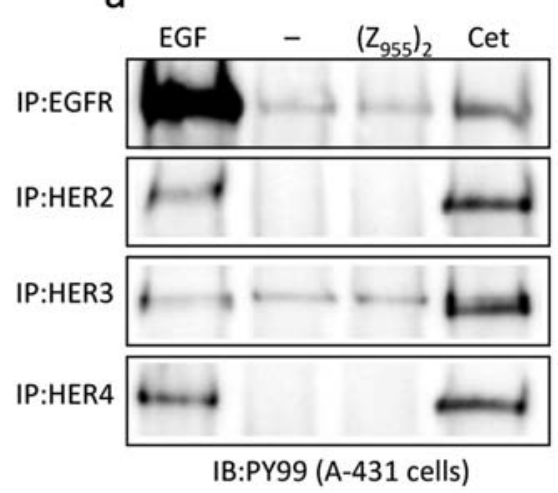

b

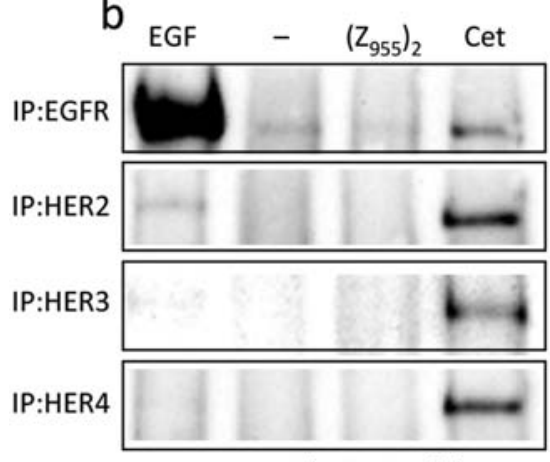

IB:PY99 (U-343 cells)
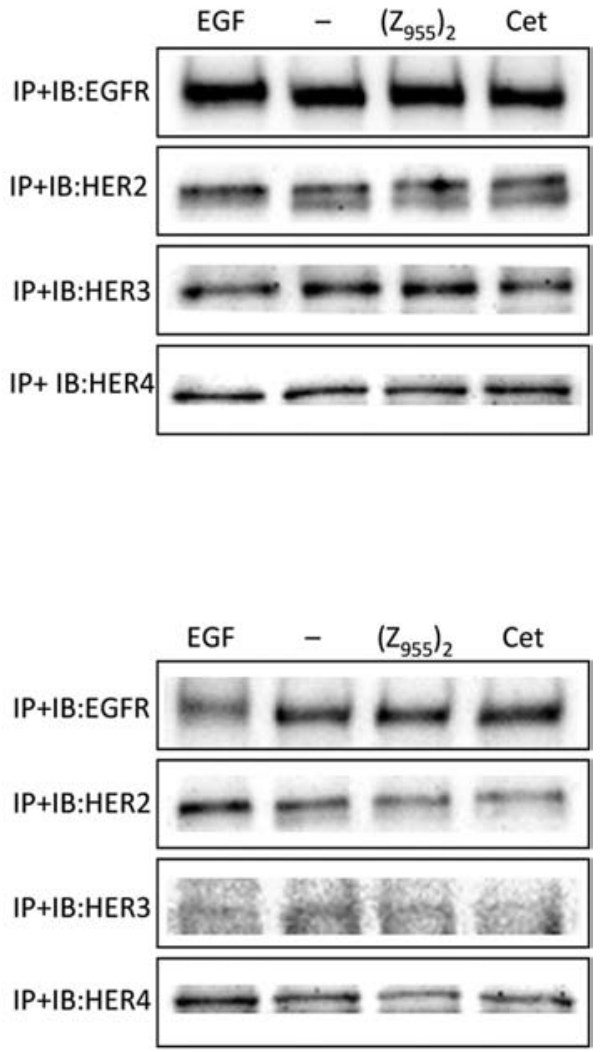

Figure 4. Phosphorylated and total EGFR and HER2-4 in A-431 (a) and U-343 (b) cells. Phosphorylations are shown to the left and total receptor amount to the right. EGF autophosphorylated all four receptors in A-431 cells, and clearly most in EGFR. In U-343 cells a strong autophosphorylation could be seen in EGFR and a weak in HER2, while no signal could be detected in HER3 or HER4. (Z $Z_{\text {EGFR:955) }}$ did not induce autophosphorylation in any receptor in the EGFR-family, as compared to the controls, while cetuximab did that for all four receptors in both cell lines. Untreated cells were controls (-). 


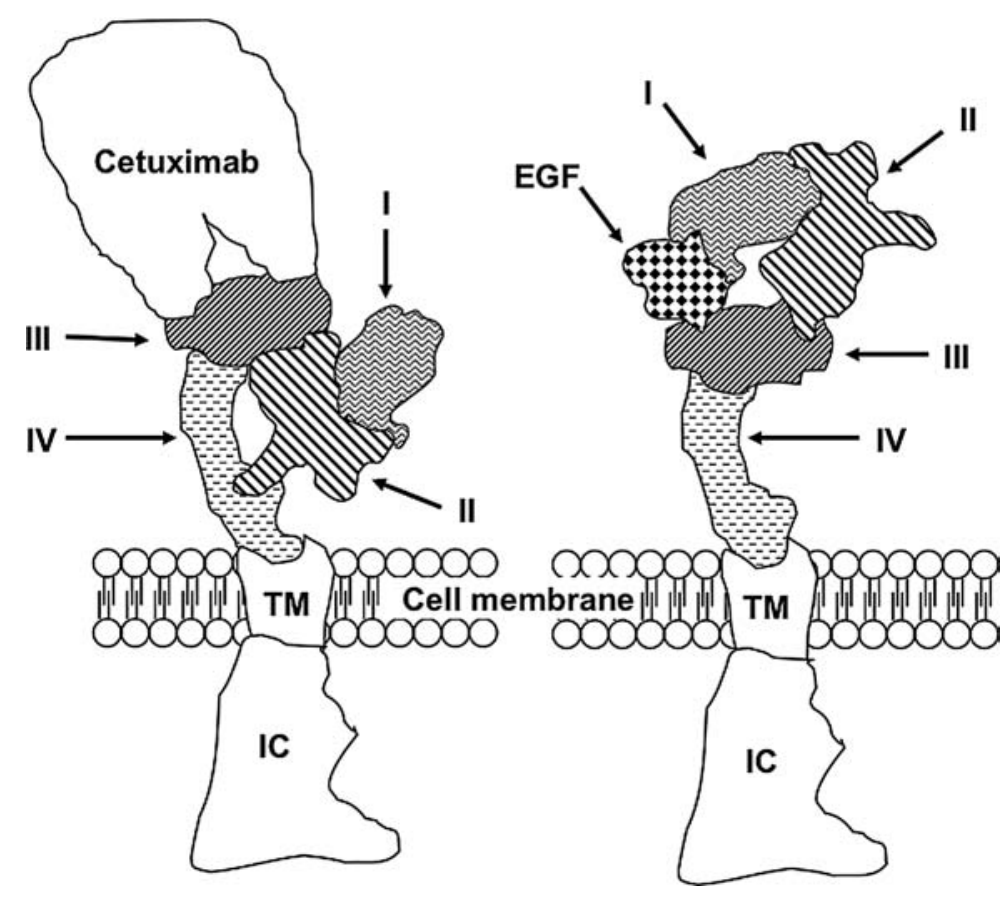

Figure 5. Schematic illustration of assumed binding of EGF and cetuximab to domain III of EGFR. The extracellular domains of EGFR are marked I-IV, the transmembrane region is marked TM and the intracellular region IC. Cetuximab binds a large part of domain III and blocks the binding of both EGFR and $\left(\mathrm{Z}_{\mathrm{EGFR}: 955}\right)_{2}$, as indicated on the left. EGF binds to both domains I and III, and thereby allow the dimerization region of domain II to be exposed to surrounding receptors, as indicated on the right. Both EGF and cetuximab inhibit the binding of $\left(\mathrm{Z}_{\mathrm{EGFR}: 955}\right)_{2}$ to EGFR as is shown in a previous study (18).

with $\left(\mathrm{Z}_{\mathrm{EGFR}: 955}\right)_{2}$, was caused by interactions between EGFR and other receptors in the EGFR-family. Cetuximab and EGF were again used as reference molecules.

In the A-431 cell line autophosphorylation could be detected in all four receptors when treated with EGF, although strongest in EGFR and only to very low levels in HER2 and HER3 (Fig. 4a). U-343 cells treated with EGF demonstrated strong EGFR and weak HER2 autophosphorylation while no induced autophosphorylation could be detected in HER3 or HER4 (Fig. 4b).

No induced autophosphorylation could be detected in any of the receptors in the two cell lines after treatment with $\left(\mathrm{Z}_{\text {EGFR:955 }}\right)_{2}$. Note that, in this case, the weak autophosphorylation bands for EGFR and HER3 in A-431 cells were also present in the non-exposed controls, thus $\left(\mathrm{Z}_{\mathrm{EGFR}: 955}\right)_{2}$ did not induce these weak signals. Cetuximab induced autophosphorylation of all receptors in both cell lines (Fig. 4).

\section{Discussion}

In the present study, we investigated the biological effects of the EGFR targeting affibody molecule $\left(\mathrm{Z}_{\text {EGFR:955 }}\right)_{2}$ on intracellular signaling, more specifically the phosphorylation levels of EGFR, HER2-4, Erk and Akt. The results were compared to that of the natural ligand EGF and the clinically used antibody cetuximab. The reference molecules EGF and cetuximab compete for the same binding site, most likely to subdomain III (Fig. 5), on EGFR as $\left(\mathrm{Z}_{\mathrm{EGFR}: 955}\right)_{2}(18)$, and may therefore share signaling abilities.

The results of the experiments made on two different cell lines, A-431 and U-343 both expressing high levels of EGFR, demonstrated that the signaling patterns were not the same for the three analyzed substances. As expected, EGFR showed strong autophosphorylation in response to EGF already after $5 \mathrm{~min}$ in both cell lines. However, when we incubated the cells with the affibody molecule $\left(\mathrm{Z}_{\mathrm{EGFR}: 955}\right)_{2}$, no induced autophosphorylation of EGFR could be detected, whereas cetuximab treatment resulted in modest EGFR autophosphorylation. Thus, despite the fact that all three substances target EGFR, and probably the same subdomain (18), their ability to activate the EGFR receptor differed dramatically. One could speculate that the failed autophosphorylation indicates inability of the affibody molecule to trigger receptor dimerization or that the affibody molecule dimerizes the receptor in a way that does not permit for auto- or transphosphorylation.

Activation of the downstream signaling molecules Erk and Akt (the Akt pathway was inducible in A-431 cells but was constantly activated in U-343 cells) by ( $\left.\mathrm{Z}_{\mathrm{EGFR}: 955}\right)_{2}$ was surprising considering that this molecule seemed unable to induce EGFR autophosphorylation. The phenomenon that Erk can be activated without any detectable EGFR autophosphorylation has, to the knowledge of the authors, earlier only been observed in one study and that was in A-431 cells exposed to Et-18-OCH3 (alkyl-lysophospholipids, ALP) (21). This paradox may be resolved by assuming that very low levels, not detectable with the applied methods, of autophosphorylated EGFR are sufficient to induce activation of Erk and Akt. In our case, another explanation could be that $\left(\mathrm{Z}_{\mathrm{EGFR}: 955}\right)_{2}$ binds to EGFR in such a way that EGFR interacts with the other receptors in the EGFR-family (1-4,22), or even with receptors in other protein tyrosine kinase (PTK) families, and that activation of Erk and Akt thereby can take place without autophosphorylation of EGFR. The other receptors 
in the EGFR-family was however analyzed and neither of them showed any sign of phosphorylation when the cells were treated with $\left(\mathrm{Z}_{\mathrm{EGFR}: 955}\right)_{2}$ (Fig. 4). A third, but less likely possibility is that the affibody molecule induces EGFR autophosphorylation that is not detected by the phosphotyrosine antibody.

It would be interesting to study whether $\left(\mathrm{Z}_{\mathrm{EGFR}: 955}\right)_{2}$ can modify effects of chemotherapy and radiotherapy. Cetuximab can sensitize radiation effects $(23,24)$ and can reverse resistance to the cytotoxic drug irinotecan (25). Studies exploring whether the affibody molecule $\left(Z_{\mathrm{EGFR}: 955}\right)_{2}$ is a radiosensitizer are planned at our laboratories.

In conclusion, the affibody molecule $\left(\mathrm{Z}_{\mathrm{EGFR}: 955}\right)_{2}$ gave no detectable autophosphorylation of EGFR but activated Erk and Akt (with the exception that Akt was constitutively activated in the U-343 cells). The clinically used antibody cetuximab showed similar downstream signaling patterns (i.e. Erk and $\mathrm{Akt})$ as $\left(\mathrm{Z}_{\mathrm{EGFR}: 955}\right)_{2}$. One important difference was that cetuximab also was able to autophosphorylate all four receptors in the EGFR-family (Fig. 4). Thus, our results suggest that the signaling pattern induced by $\left(\mathrm{Z}_{\mathrm{EGFR}: 955}\right)_{2}$ is only partly similar to that induced by cetuximab. This makes the affibody molecule a potentially interesting candidate for EGFR targeting therapy since it might have different effects on tumor cells and different side effects on normal tissues. However, more research is needed to evaluate the mechanism behind the activation of Erk and Akt as induced by the affibody molecule since it was obtained without detectable EGFR autophosphorylation.

\section{Acknowledgements}

This study was funded by grant P25882-1 from the Swedish Governmental Agency for Innovative Systems (VINNOVA) and grants 0980-B07-20XCC and B06-24XCC from the Swedish Cancer Society.

\section{References}

1. Bublil EM and Yarden Y: The EGF receptor family: spearheading a merger of signaling and therapeutics. Curr Opin Cell Biol 19: 124-134, 2007.

2. Baselga $J$ and Arteaga CL: Critical update and emerging trends in epidermal growth factor receptor targeting in cancer. J Clin Oncol 23: 2445-2459, 2005.

3. Harari PM: Epidermal growth factor receptor inhibition strategies in oncology. Endocr Relat Cancer 11: 689-708, 2004.

4. Marmor MD, Skaria KB and Yarden Y: Signal transduction and oncogenesis by ErbB/HER receptors. Int J Radiat Oncol Biol Phys 58: 903-913, 2004.

5. Normanno N, De Luca A, Bianco C, Strizzi L, Mancino M, Maiello MR, Carotenuto A, De Feo G, Caponigro F and Salomon DS: Epidermal growth factor receptor (EGFR) signaling in cancer. Gene 366: 2-16, 2006.

6. Marshall J: Clinical implications of the mechanism of epidermal growth factor receptor inhibitors. Cancer 107: 12071218, 2006.

7. Mendelsohn J and Baselga J: Status of epidermal growth factor receptor antagonists in the biology and treatment of cancer. J Clin Oncol 21: 2787-2799, 2003.

8. Dutta PR and Maity A: Cellular responses to EGFR inhibitors and their relevance to cancer therapy. Cancer Lett 254: 165-177, 2007.

9. Sebastian S, Settleman J, Reshkin SJ, Azzariti A, Bellizzi A and Paradiso A: The complexity of targeting EGFR signaling in cancer: from expression to turnover. Biochim Biophys Acta 1766: 120-139, 2006.
10. Citri A and Yarden Y: EGF-ERBB signaling: towards the systems level. Nat Rev Mol Cell Biol 7: 505-516, 2006.

11. Hynes NE and Lane HA: ERBB receptors and cancer: the complexity of targeted inhibitors. Nat Rev Cancer 5: 341-354, 2005.

12. Matar P, Rojo F, Cassia R, Moreno-Bueno G, Di Cosimo S, Tabernero J, Guzmán M, Rodriguez S, Arribas J, Palacios J and Baselga J: Combined epidermal growth factor receptor targeting with the tyrosine kinase inhibitor gefitinib (ZD1839) and the monoclonal antibody cetuximab (IMC-C225): superiority over single-agent receptor targeting. Clin Cancer Res 10: 6487-6501, 2004.

13. Nord K, Gunneriusson E, Ringdahl J, Stahl S, Uhlen M and Nygren PA: Binding proteins selected from combinatorial libraries of an alpha-helical bacterial receptor domain. Nat Biotechnol 15: 772-777, 1997.

14. Steffen AC, Orlova A, Wikman M, Nilsson FY, Stahl S, Adams GP, Tolmachev V and Carlsson J: Affibody-mediated tumour targeting of HER-2 expressing xenografts in mice. Eur J Nucl Med Mol Imaging 33: 631-638, 2006.

15. Baum R, Orlova A, Tolmachev V and Feldwisch J: A novel molecular imaging agent for diagnosis of recurrent HER2 positive breast cancer. First time in human study using an Indium-111or Gallium-68-labeled molecule. Eur J Nucl Med Mol Imaging 33: 91-92, 2006.

16. Baum R, Tolmachev V and Feldwisch J: Receptor PET/CT and SPECT using an affibody molecule for targeting and molecular imaging of HER2 positive cancer in animal xenografts and human breast cancer patients. J Nucl Med 47 (Suppl 1): 108, 2006.

17. Nordberg E, Orlova A, Friedman M, Tolmachev V, Ståhl S, Nilsson FY, Glimelius B and Carlsson J: In vivo and in vitro uptake of ${ }^{111} \mathrm{In}$, delivered with the affibody molecule $\left(\mathrm{Z}_{\mathrm{EGFR}: 955}\right)_{2}$, in EGFR expressing tumour cells. Oncol Rep 19: 853-857, 2008.

18. Nordberg E, Friedman M, Göstring L, Adams GP, Brismar H, Nilsson FY, Ståhl S, Glimelius B and Carlsson J: Cellular studies of binding, internalization and retention of a radiolabeled EGFR-binding affibody molecule. Nucl Med Biol 34: 609-618, 2007.

19. Westermark B, Magnusson A and Heldin CH: Effect of epidermal growth factor on membrane motility and cell locomotion in cultures of human clonal glioma cells. J Neurosci Res 8: 491-507, 1982.

20. Lennartsson J, Blume-Jensen P, Hermanson M, Ponten E, Carlberg M and Ronnstrand L: Phosphorylation of She by Src family kinases is necessary for stem cell factor receptor/c-kit mediated activation of the Ras/MAP kinase pathway and c-fos induction. Oncogene 18: 5546-5553, 1999.

21. Ruiter GA, Verheij M, Zerp SF, Moolenaar WH and Van Blitterswijk WJ: Submicromolar doses of alkyllysophospholipids induce rapid internalization, but not activation, of epidermal growth factor receptor and concomitant MAPK/ERK activation in A431 cells. Int J Cancer 102: 343-350, 2002.

22. Sergina NV, Rausch M, Wang D, Blair J, Hann B, Shokat KM and Moasser MM: Escape from HER-family tyrosine kinase inhibitor therapy by the kinase-inactive HER3. Nature 445 : 437-441, 2007.

23. Raben D, Helfrich B, Chan DC, Ciardiello F, Zhao L, Franklin W, Barón AE, Zeng C, Johnson TK and Bunn PA Jr: The effects of cetuximab alone and in combination with radiation and/or chemotherapy in lung cancer. Clin Cancer Res 11: 795-805, 2005.

24. Bonner JA, Harari PM, Giralt J, Azarnia N, Shin DM, Cohen RB, Jones CU, Sur R, Raben D, Jassem J, Ove R, Kies MS, Baselga J, Youssoufian H, Amellal N, Rowinsky EK and Ang KK: Radiotherapy plus cetuximab for squamous-cell carcinoma of the head and neck. N Engl J Med 354: 567-578, 2006.

25. Cunningham D, Humblet Y, Siena S, Khayat D, Bleiberg H, Santoro A, Bets D, Mueser M, Harstrick A, Verslype C, Chau I and Van Cutsem E: Cetuximab monotherapy and cetuximab plus irinotecan in irinotecan-refractory metastatic colorectal cancer. N Engl J Med 351: 337-345, 2004. 